World Lumen Congress 2021 | May 26-30, 2021 |

Iasi, Romania

\title{
Cartographic Analysis of the Radon Situation in the Environment
}

\author{
Renat APKIN
}

https://doi.org/10.18662/wlc2021/03

How to cite: Apkin, R. (2021). Cartographic Analysis of the Radon Situation in the Environment. In A. Sandu (vol. ed.), Lumen Proceedings: Vol. 17 World Lumen Congress 2021 (pp. 26-33). Iasi, Romania: LUMEN Publishing House. https://doi.org/10.18662/wlc2021/03 


\title{
Cartographic Analysis of the Radon Situation in the Environment
}

\author{
Renat APKIN 1
}

Abstract

According to UNSCEAR (United Nations Scientific Committee on the Effects of Atomic Radiations), no less than $10 \%$ of lung cancer diseases registered annually are caused by radon radiation. Born in the belly of the earth, the same gas, a class I carcinogen, increases the risk of non-cancerous diseases of the upper respiratory tract and cardiovascular diseases. The radon problem occupies an important place in the radioecological programs of the USA, Japan, Western Europe and Russia.

However, the natural radiation varies in the background from location to location.

In many countries, survey work is being carried out, including an assessment of the intensity of the radon hazards of sites allocated for construction.

In Russia, the Radiation Safety Standards are stipulating that the concentration of radon in the air of residential premises should not exceed $200 \mathrm{~Bq} / \mathrm{m3}$; in Sweden, the maximum radon concentration is taken as $100 \mathrm{~Bq} / \mathrm{m}^{3}$, in Finland and Canada $-400 \mathrm{~Bq} / \mathrm{m}^{3}$, and in Germany and Great Britain - $200 \mathrm{~Bq} / \mathrm{m}^{3}$. It is necessary to carefully choose the constructive site, with the minimum concentration of radon in the soil.

Our purpose is to carry out a cartographic analysis of radon intake from soil in the territory of Kazan. An important component is the creation of unique maps based on the measurement of radon exhalation.

The practical significance of the work lies in the application of the results for making management decisions, in engineering and environmental surveys, for conducting bygienic assessments, or simply being used by citizens for informational purposes.

Keywords: Radon, lung cancer, hazard, cartographic analysis, environmental surveys, bygienic assessment.

\footnotetext{
${ }^{1}$ Associate Professor PhD, Kazan Station Power Engineering University, Kazan, Russia. E-mail: renat.apkin@gmail.com
} 


\section{Introduction}

The radon problem has an acute impact on human health.

The aim of this paper is to analyze the risk of radiation hazard in industry and in domestic conditions by applying cartographic methods to interpret our data of measuring radon exhalation in the soil air existing in residential and industrial buildings on the primer of Kazan, the capital city of Tatarstan.

Radon gas is part of the Earth's natural background radiation which varies from location to location. Also, the concentration of radon in different parts of the Earth is not the same. Forming in the bowels of the Earth, it accumulates in rocks and then gradually moves along cracks to the surface of the Earth, thus getting into the human environment.

According to Schmid et al. (2010): "It is well documented in the scientific literature that indoor radon significantly increases the risk of lung cancer, probably in a linear dose-response relationship with no threshold. Every $100100 \mathrm{~Bq} / \mathrm{m}^{3}$ increase in the radon concentration is estimated to increase the relative risk for lung cancer by $8 \%$ to $16 \%$.

To predict the potential radon hazard in the territories, it is necessary to study the tectonic activity, geological structure, hydrogeological conditions of the area, the properties of rocks, e.g. the concentration of radium, the distribution of the volumetric activity of radon in the soil air in order to identify the main sources of emanation, their position in the section and the nature of the transfer of radon from sources to the surface of the earth.

The research results obtained make it possible to identify the following types of territories:

- Potentially radon-hazardous areas, where there is a possibility, under a certain combination of natural factors, that the density of radon flux from the soil and the volumetric activity of radon in the air of the designed buildings and other structures will exceed the regulatory normatives. The main feature of such territories is the presence of a constant and sufficiently powerful source of radon emission. These are areas with bedding of rocks close to the surface, characterized by relatively high concentrations of radium (clays, shales, weathered granites, rocks with signs of uranium mineralization), low thickness (up to 10 meters) and good permeability of the overlying rocks, as well as areas of crystalline shields and folded belts with active tectonics, widespread faults, radon water outputs, etc.

- Radon-safe areas, in which, practically with any combination of natural factors, the density of radon flux from the soil and radon concentration in the premises of the projected buildings does not exceed the regulatory limits. These are areas in which the rocks (zones, structures) that can act as significant sources of emanation, either are absent or overlain by thick strata of poorly permeable or water-bearing sediments.

In the territory study, radon can move to the surface of the earth from the source of exhalation to a distance not exceeding 2-3 meters in clay soils, and 10 meters in sandy soils. Therefore, when assessing the radon hazard of the territories of the projected construction (at the stage of design and working documentation), it 
is necessary to determine the concentration of radium $(226 \mathrm{Ra})$ in the soils lying at a depth of up to 10 meters below the basement level.

If in the section there are soils that are potential sources of exhalation (up to the indicated depth), there is a certain probability of increased radon fluxes from the soil into the basement of the designed structure at the site. When assessing the intensity of radon emission from the soil, it is necessary to carry out measurements not only on the day surface, but mainly on the bottom and the sides of the trench (depending on the position of the sources of radon emission).

If the results of these measurements exceed the normatives, the site can be considered potentially radioactive. The design of the protection should be carried out taking into account the position of soil horizons in the section that are the sources of radon.

In the late 90s of the last century, the scientific interest in studying radon (222Rn), especially the value of the radon flux density (RFD) has significantly increased. Basically, this was associated with the use of the RFD value for assessing the potential radon hazard of territories in such areas as radioecology, geoecology, and construction. Based on the data on the measured values of the SPR, maps of the radon potential of the territories were constructed for the purpose of subsequent assessments of the radiation risk for the population. For example, new methodology was proposed by Ielsch et al. (2002), for predicting areas with a strong potential for radon exhalation, applied in the territories of Western France. "This methodology is based on the Rn exhalation rate quantification, starting from a precise characterisation of the main local geological and pedological parameters that control the radon source and its transport to the soil/atmosphere interface. It combines a cross mapping analysis of these parameters into a geographic information system with a model of the Rn vertical transport by diffusion in the soil" (Ielsch et al., 2002). The authors show that "the radon-prone sectors identified by this approach generally correspond to the location of the dwellings showing the highest radon concentrations", (Ielsch et al., 2002), which is a most useful information.

Original methods were applied to receive new data on radon, also in France, by Saâdi and Guillevic (2016): “....we demonstrate how to quantify ... uncertainties by comparing simulation results from two different numerical models to experimental data of radon exhalation rate and activity concentration in the soil-gas measured in a covered UMT-soil near the landfill site Lavaugrasse".

A group of Italian scholars, Lucchetti et al. (2019), report on integrated data obtained on radon flux and another radioactive gas, thoron, in Rome. "A map of total gamma radiation... and 9 vertical gamma profiles have been carried out, showing that the main control of gamma levels is, of course, the lithological nature, without neglecting the simultaneous effect of other parameters such as slope morphology, erosion/weathering processes, occurrence of sinkholes or underground tunnels"(Lucchetti et al., 2019). Such surveys, for instance, allowed to recognize the localities with abnormally high radiation in fluvial valleys.

There is also a research taken up in Germany: Bossew (2015) reports on a geological method of measuring indoor radon concentration concerning the houses 
built on a certain site: "A radon prone geology is one for which the probability is increased that in a house built on it, elevated indoor $\mathrm{Rn}$ concentration will be encountered, or that its Rn potential will be increased" (Bossew, 2015).

Shortly, in most industrially developed countries, as the USA, France, Germany etc., radon problem has long been coped with, while not really in Russia, where the corresponding research is considerably new; whereas it is of utmost importance. To cite Bossew's wording once again: “Labelling geological units as Rn prone or not can be an important support in deciding whether a geographical or administrative region in which that geological unit occurs, should be called Rn prone area, possibly in absence of other predictors"(Bossew, 2015).

\section{Methods}

In this paper, an attempt is made to identify the regularities of radon exhalation depending on the natural conditions in the city of Kazan, Tatarstan, Russia. Developing the series of thematic maps with points marking the places of measuring the volumetric activity of radon in the soil air is an important part of this work.

The data of measurements of the volumetric activity of radon in the soil air in the territory of the city of Kazan and its environs were used as the initial data in the work. The measurements were carried out with an RTM 1688-2 GeoStation device manufactured by SARAD GmbH (Germany) at 57 control points.

Geo-information systems QGIS and ArcGIS were used to create maps of various topics to analyze the escalation of radon on the territory of the city of Kazan. The result of the work is shown in Figures 1-4.

Based on a detailed examination of the maps obtained, it can be concluded that the northeastern and southern parts of Kazan are radon-hazardous. In the southern part of Kazan, there are most of the residential suburban sectors ("dachas"), the houses are mostly one-story, so the risk of radon getting into the dwelling is great. Having learned the sources of radon entry into the environment and residential buildings, it is necessary to develop the means of counteracting and combating this undesirable phenomenon. These consist in following the certain rules: coverings;

- pay sufficient attention to the sealing of basements, floors and floor

- treat with mastics and sealants the cracks and pores in walls and ceilings, then paint these with materials based on epoxy resin and other facing material;

- stay away from the unventilated areas of the house, i.e., in the basement or cellar (or do not stay there for a long time);

- organize regular natural ventilation of living rooms and basements;

- arrange some effective forced ventilation of the house or apartment;

- boil water taken from deep springs, and do not drink it raw, since radon can be contained in groundwater;

- use charcoal filters for water purification, which allow trapping radon by 90 percent; 
Renat APKIN | Lumen Proceedings 17 | WLC 2021

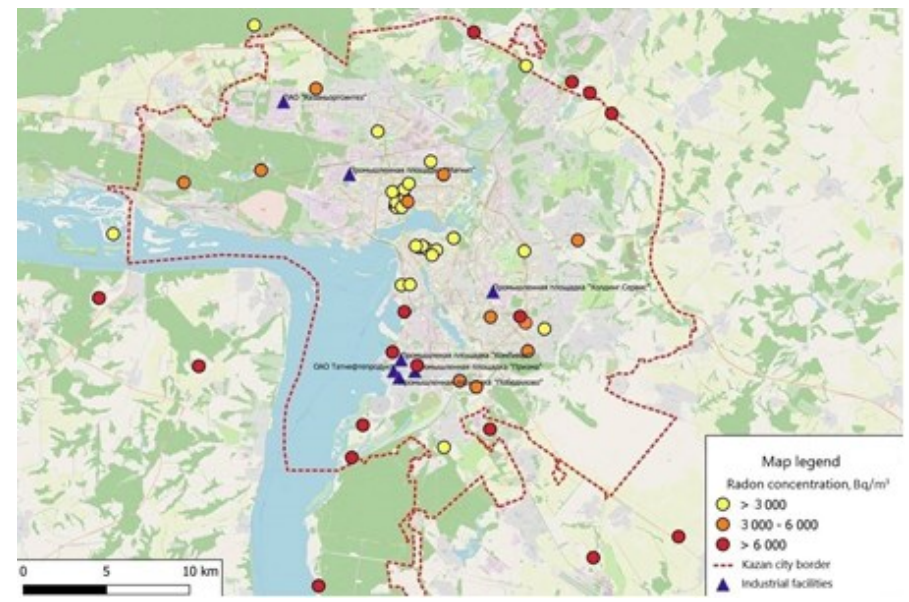

Fig. 1. Points of measurement of radon concentration on a general geographic map

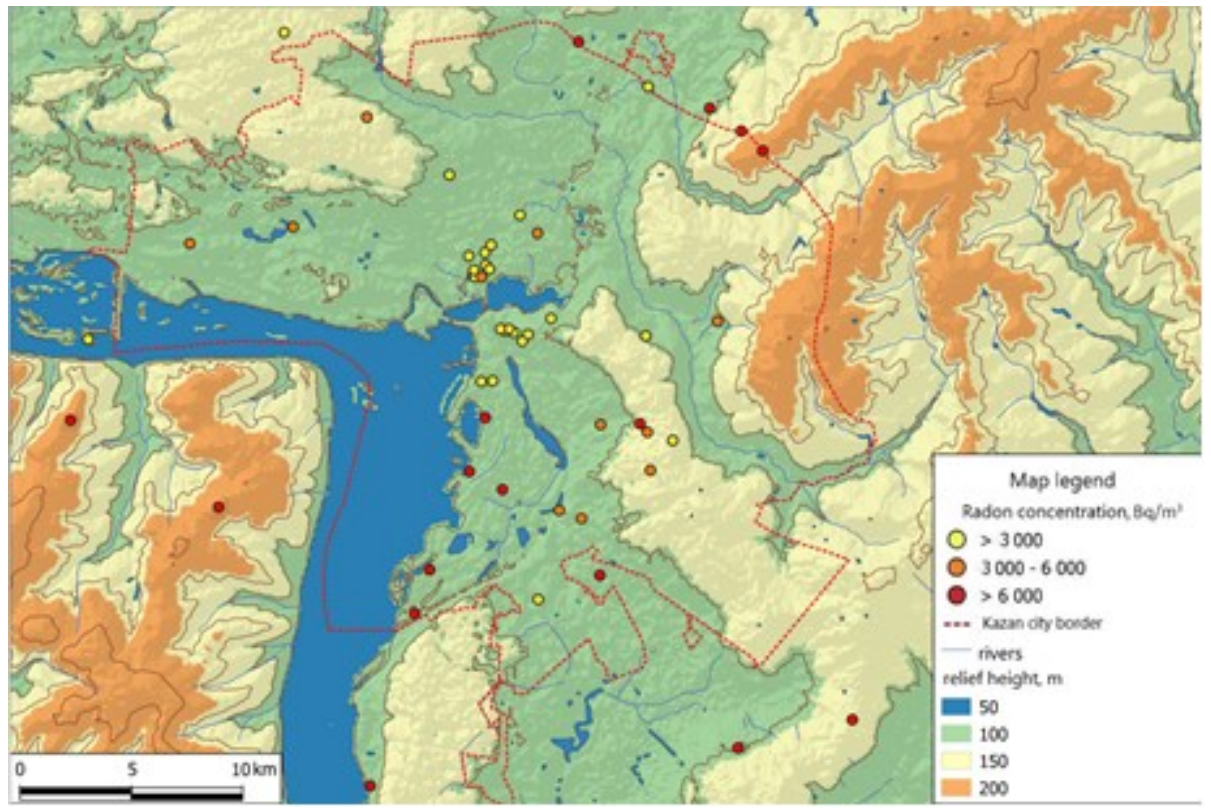

Fig. 2. Points of measurement of radon concentration on a hypsometric map 


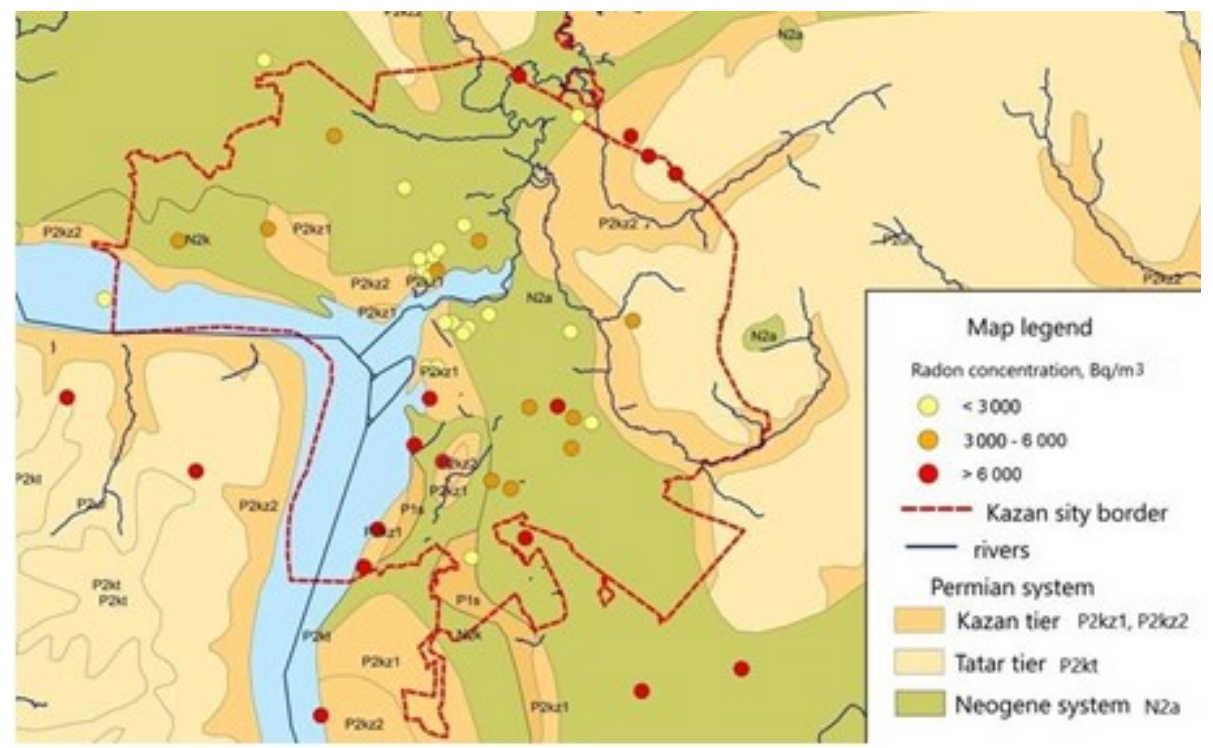

Fig. 3. Points of measurement of radon concentration on a geological map

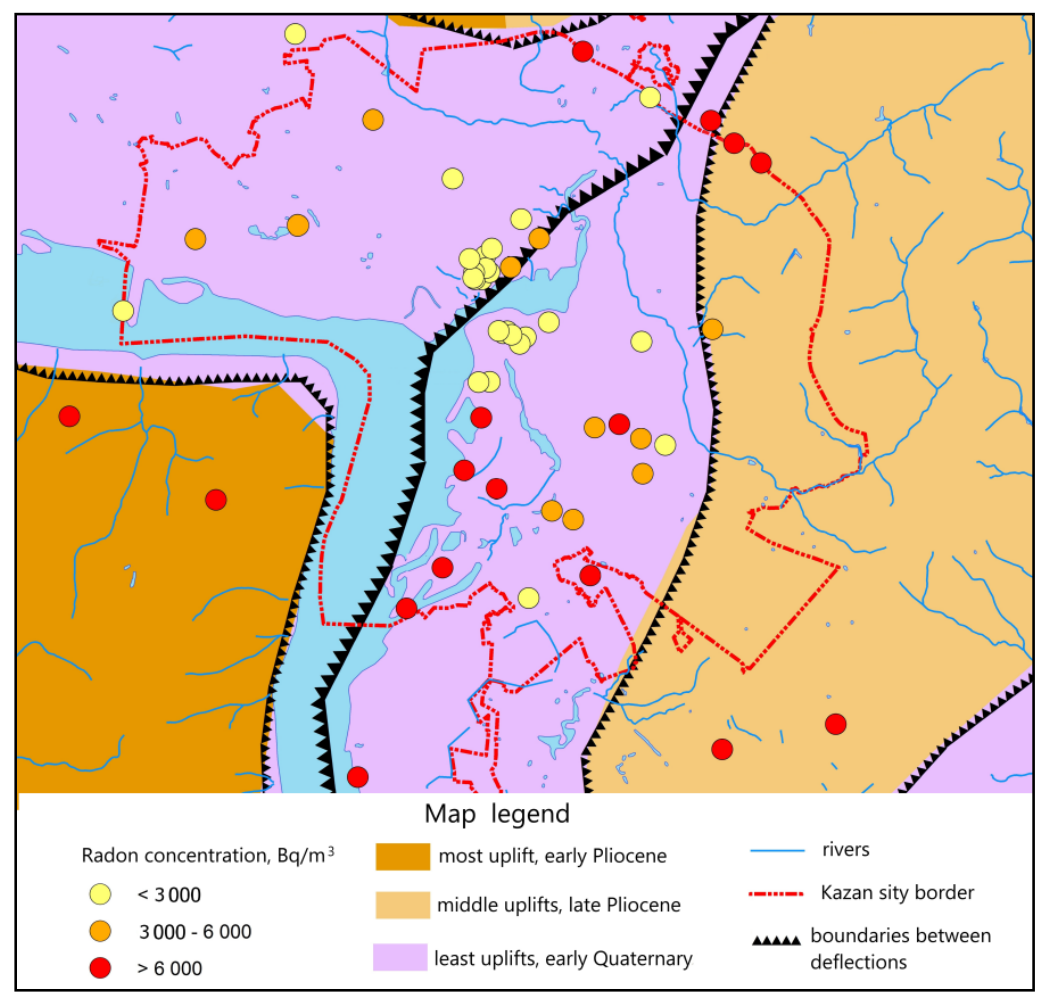

Fig. 4. Points of measurement of radon concentration on a tectonic map

- reduce the time spent in the shower room, take a shower less often, arrange mandatory ventilation before using the shower by other family members; 
- equip an exhaust ventilation system above the gas stove (Bekman, 2010).

In addition, it is necessary to carry out systematic monitoring of radon concentration in various areas of the house in order to identify dangerous places. Having an individual device at hand, one can evaluate the effectiveness of countermeasures carried out in houses where people live. The assessment of the amount of accumulated radon in the room is carried out immediately before the event and after its implementation. The obtained values are compared with each other. These measurements should be made under the same conditions, taking into account the natural movement of air due to drafts, closed or open doors and windows, and the functioning of the ventilation system.

The analysis of the escalation of radon in the territory of the city of Kazan was carried out using the cartographic method, namely, considering the dispersion of the concentration of radon in the soil air.

It was found out that the geological space under the buildings, the used materials, as well as water and gas in domestic conditions do serve the sources of radon. In different regions, the influence of each factor has its own specificity, which depends on the geological structure including the distribution of natural radioactive elements in rocks, soils and groundwater, as well as the presence of tectonic faults.

\section{Conclusion}

The scientific and - wider - social importance of the work done, as well as of the perspectives of utilizing this experience, seems very high. It provides for the opportunity to safeguard the health and well-being of population, especially in the industrially developed countries, by using cartographic methods while analyzing the treats of the radon situation in the environment. Certainly first it should be practical measuring the exhalation in given areas; but practice is not always available "in the field" ("in situ") and it should be substituted by studying the models, in our cases, manifold maps. It is the first or one of the first times that the example is produced, of performing such kind of research on the basis of Kazan city maps. It allowed us to enhance significantly the data of the soil evaporation, which can have a great impact on the estimation of the average measured radon exhalation rate in general.

This experience has great prospects for its application. Analysis of these our materials should be taken into account when assessing the risk of radiation hazard both in industry and in domestic conditions. In particular, it is necessary to carefully consider the possible accumulation of radon in existing residential and industrial buildings, and an advanced study of the concentration of radon in the soil air (or radon flux from the soil) should be carried out while constructing the new facilities.

It is worth noting the advantages and prospects of using the mapping method to present the results of the study of the radon situation. First, they provide for the clarity in presenting the results, which allows finding out the most dangerous areas. Secondly, of note is the convenience of this method for considering the influence of various factors on the concentration of radon in the soil air. Analysis of 
thematic maps with overlaid points of measurement of the volumetric activity of radon makes it possible to trace the dependence on natural geological, tectonic, and structural factors. Thirdly, this method allows one to process large amounts of monitoring data. The resulting material would serve as a basis for the future studies related to the radon situation. It is also important to use it in the process of environmental engineering surveys for the construction of would-be buildings.

In general, there is no value higher than human life. So, to discover the indoor radon exhalation and map the radon prone territories means you can distinguish safe (or dangerous) sites for living and working, which is of enormous social significance, both for Russia and any other country.

\section{References}

Bekman I. N. (2010) Radon v zhilyh pomesheniyah [Radon in living quarters]. Radon: vrag, vrach i pomoshnik. Kurs lekecii. https://www.studmed.ru/bekman-in-radon-vragvrach-i-pomoschnik-kurs-lekciy 2909dd1c5aa.html

Bossew P. (2015). Estimation of radon prone areas through binary classification, part 2: radon prone geologies. Journal of Environmental Radioactivity, 141, 44-50. http://doi.org/10.1016/j.jenvrad.2014.11.020

Ielsch G., Ferry C., Tymen G., \& Robe M. C. (2002). Study of a predictive methodology for quantification and mapping of the radon 222 exhalation rate. Journal of Environmental Radioactivity, 63, 15-33. https://doi.org/10.1016/s0265-931x(01)00133-3

Lucchetti, C., Briganti, A., Castelluccio, M., Galli, G., Santilli, S., Soligo, M., \& Tuccimei, P. (2019). Integrating radon and thoron flux data with gamma radiation mapping in radon-prone areas. The case of volcanic outcrops in a highly-urbanized city (Roma, Italy). Journal of Environmental Radioactivity, 202, 41-50. http://doi.org/10.1016/j.jenvrad. 2019.02.004

Saâdi, Z., \& Guillevic, J. (2016). Comparison of two numerical modelling approaches to a field experiment of unsaturated radon transport in a covered uranium mill tailings soil (Lavaugrasse, France). Journal of Environmental Radioactivity, 151, 361-372. http://doi.org/10.1016/j.jenvrad.2015.03.019

Schmid, K., Kuwert, T., \& Drexler, H. (2010). Radon in indoor spaces: an underestimated risk factor for lung cancer in environmental medicine. Dtsch Aratebl Int, March, 107(11), 181-186. http://doi.org/10.3238/arztebl.2010.0181 